www.jmscr.igmpublication.org Impact Factor 5.84

Index Copernicus Value: 83.27

ISSN (e)-2347-176x ISSN (p) 2455-0450 crossref DOI: _https://dx.doi.org/10.18535/jmscr/v5i4.210

\title{
Prevalence and Pattern of Direct Gynecological Morbidity among Postmenopausal Women Aged Above 50 - A Community Study
}

\author{
Authors \\ Dr S. Sreelatha ${ }^{1}$, Dr Shahanas Hassan $\mathbf{H}^{2}$, Dr Shaila $\mathbf{S}^{3}$ \\ ${ }^{1}$ Addl. Professor, Sree Avittom Thirunal Hospital, Govt. Medical College, Trivandrum \\ ${ }^{2}$ Former Post Graduate Student, Dept. of O and G, Sree Avittom Thirunal Hospital, Govt. Medical College, \\ Trivandrum \\ ${ }^{3}$ Professor, Dept. of O and G, Sree Avittom Thirunal Hospital, Govt. Medical College, Trivandrum \\ Corresponding Author \\ Dr S. Sreelatha \\ Addl. Professor, Sree Avittom Thirunal Hospital, Govt. Medical College, Trivandrum
}

\begin{abstract}
Background: Gynecological morbidity is one of the three facets of reproductive morbidity as enlisted by WHO. The aim of this study is to understand the prevalence and pattern of direct gynecological morbidity among postmenopausal women aged above 50years in an urban setting in Trivandrum district.

Materials and Methods: The study was done in two randomly selected wards of Trivandrum district. Sample size derived was 400. Systematic sampling was done to select the study households. From the study household postmenopausal women above 50 consenting for study was selected. Mentally challenged and bedridden women were excluded. Phase one was an interview at the woman's house and phase two was a gynecological examination including cervical smear at the nearest facility which was Government Medical College Trivandrum. Data was collected and analyzed.

Results and Discussion: The prevalence of self-reported gynecological symptoms was $19 \%$ in the study population and the gynecological morbidity computed by examination was 23.5\%. This was low when compared to other studies. The probable reason could be that this study population was the educated, urban, middleclass women with easy accessible health facility. The most frequent symptom was those involving the urinary tract (12.3\%) and the morbidity was diseases of the vulva and vagina. Younger age of menarche and lower socioeconomic status was found to have significant association with the prevalence of gynecological symptoms.
\end{abstract}

\section{Back ground}

Reproductive morbidity was redefined after the ICPD conference in 1994 in Cairo ${ }^{(1)}$ Rather than confining to a particular phase in the life of a woman, it was to include the whole life cycle. For many women her postmenopausal life years may exceed her reproductive life years as the life expectancy has increased (2) Often the health problems, especially the reproductive tract related problems of the post-menopausal women may go unaddressed in Kerala too in spite of the high health indices. This may lead to late diagnosis of 
grave diseases like malignancies which may hamper the survival of many and in the survivors, the quality of life. Many women may be suffering from various chronic urogenital morbidities which they are reluctant to reveal but may be silent killers of their self-esteem and even longevity.

Gynecological morbidity is one of the three facets of reproductive morbidity as enlisted by WHO in $1992^{(3)}$ It consists of any condition, disease or dysfunction of the reproductive system which is not related to a particular pregnancy, abortion or childbirth but may be related to sexual behavior. It is subdivided into direct, indirect and psychological morbidity. The aim of this study was to understand the prevalence and pattern of direct gynecological morbidity among postmenopausal women above 50 years in an urban setting in Trivandrum district.

Hospital based studies do not reflect the true magnitude of the disease burden and may even overestimate. They do not provide information on social, demographic or economic determinants. Hence this community based study.

\section{Materials and Methods}

This was a community based cross sectional study done in an urban setting in Trivandrum, district of Kerala. Various studies showed varying prevalence. Sample size was calculated taking a prevalence of $50 \%$ using the formula

$\mathrm{n}=4 \mathrm{pq} / \mathrm{L}^{2}$

$\mathrm{P}=$ proportion having direct gynecological morbidity in postmenopausal women aged more than 50 years

$\mathrm{q}=1-\mathrm{p}$

$\mathrm{L}=$ permissible error in the estimation of $\mathrm{P}$ (taken as $10 \%$ of $\mathrm{P}$ )

$\mathrm{p}=0.5 \%, \mathrm{q}=0.5 \%, \mathrm{n}=4 \times 0.5 \times 0.5 /(0.05)^{2}$

Final sample size was 400 .

Study was started after getting approval from the institutional research committee and ethics committee. Study period was for 2 years from 2014.

From the Field Practice Area of Government Medical College two wards were randomly chosen with a population of 11,731 and 12,853 . Systematic sampling was used to select the study households. First house was randomly selected in one ward and every fifth house was surveyed. If there was no women in the fifth house satisfying the eligibility criteria of the study then the next house was selected. This was done till the sample size reached the required 200 from each ward.

All postmenopausal women who were above 50 years and willing to participate in the study were selected. Mentally challenged women incapable of giving consent and bedridden women with chronic debilitating diseases were excluded.

In the first phase of the study, each woman was interviewed in their house and the data entered in the predesigned semi structured questionnaire by trained personnel.

In the second phase of study all participants were motivated for examination and a gynecological examination including a pap smear was done at the gynecology department of the Government Medical College Thiruvananthapuram which is the nearest health facility. Awareness regarding the gynecological problems and appropriate and adequate treatment were provided.

Data was entered into excel sheet and analysis done using SPSS 17 version. Percentage and confidence interval was looked into to estimate prevalence of reproductive morbidities. The association between variables and gynecological morbidity were assessed by deriving $p$ values using Chisquare test.

\section{Observations and Results}

Socio demographic characteristics of the study population were:

The majority of women in this study belonged to the age group of 51 to $55(65.3 \%)$. Above 60 years of age the proportion of women was $23 \%$. Above 75 there was none. Hindu women were the majority (55\%).Socioeconomic status was assessed with the modified Kuppuswamy scale. The lower middle and upper lower class together contributed to $65.5 \%$. The study group was well literate. $72.5 \%$ had high school education and 
above. Majority of women (80\%) were house wives. The family men were engaged in some sort of income earning activities except in $1 \%$ cases.

Mean age of menarche was 13 years and around $68 \%$ attained menarche by the age of 13 . All were married and majority (57\%) got married between 20-24 years age. Around $11.25 \%$ got married below the age of 20. All women were parous. Less than $1 \%$ of women had no live child while $22 \%$ had 3 or more children. Prevalence of caesarean delivery in the study group was $22.5 \%$. Last childbirth was more than 30 years back in $87 \%$ of the women. Majority (88.5\%) had menopause between $46-50$ years.

The Prevalence and pattern of Gynecological symptoms- The self-reported prevalence of gynecological symptoms was $19 \% \quad(\mathrm{n}=76)$ $(95 \% \mathrm{CI}=16-22)$. The prevalence detected by clinical examination was $23.5 \%(\mathrm{n}=94)$.

Table 1: Prevalence and pattern of gynecological symptoms and morbidity

\begin{tabular}{|c|c|c|c|}
\hline Self- reported symptoms & $\begin{array}{c}\text { Proportion } \\
\mathrm{N}=400\end{array}$ & Detected Morbidity & $\begin{array}{c}\text { Proportion } \\
\mathrm{N}=400\end{array}$ \\
\hline Urinary tract symptoms & $49(12.3 \%)$ & Diseases of vulva, vagina & $55(13.8 \%)$ \\
\hline Discharge per vaginum & $37(9.3 \%)$ & Pelvic organ prolapse & $19(4.8 \%)$ \\
\hline Mass coming down $\mathrm{p} / \mathrm{v}$ & $14(3.5 \%)$ & Stress incontinence & $20(5 \%)$ \\
\hline Sexual act related symptoms & $13(3.3 \%)$ & Diseases of cervix & $10(2.5 \%)$ \\
\hline Lower abdominal pain & $10(2.5 \%)$ & & \\
\hline Bleeding per vaginum & $3(0.8 \%)$ & & \\
\hline Total symptoms & 126 & Total morbidity & 104 \\
\hline Total women with symptoms & $76(19 \%)$ & Total women with morbidity & $94(23.5 \%)$ \\
\hline Women with one symptom & $53(13.25 \%)$ & Women with one morbidity & $86(21.5 \%)$ \\
\hline Women with two symptoms & $12(3 \%)$ & Women with 2 morbidity & $6(1.5 \%)$ \\
\hline Women with three or more symptoms & $11(2.8 \%)$ & Women with 3 or more morbidity & $2(0.5 \%)$ \\
\hline
\end{tabular}

Pattern of Gynecological symptoms: The major symptom reported by the study group was pertaining to urinary tract $(12.3 \%)$ which included burning sensation during micturition, increased frequency, urge incontinence and stress incontinence. Prevalence of discharge per vagina was $9.3 \%$ of which the predominant symptom was white discharge with or without itching. Irregular bleeding was experienced by $3 \%$ and lower abdominal pain by $3 \%$. $4 \%$ of women had a feeling of mass coming down per vagina. On examination cystocele and cystorectocele constituted a major problem $(36.8 \%$ and $26 \%$ of total pelvic organ prolapse) respectively. Sexual problems like dyspareunia and dryness was experienced by $3.3 \%$ of the subjects. On examination diseases of vulva and vagina constituted the majority of morbidity (13.8\%). Senile vaginitis was leading followed by vulvitis. Presence of erosion of cervix, and cervical polyp were noted in few women. 
Table 2: Gynecological symptoms and the association to the study variables.

\begin{tabular}{|c|c|c|c|c|c|}
\hline Serial no & Variable & $\begin{array}{l}\text { Symptoms } \\
\text { Yes }\end{array}$ & $\begin{array}{l}\text { Symptoms } \\
\text { no }\end{array}$ & $\begin{array}{l}\text { Total } \\
\mathrm{N}=400\end{array}$ & $\mathrm{x} 2$, df $\mathrm{p}$ value \\
\hline 1.Age & $\begin{array}{l}51-55 \\
56-60 \\
61-65 \\
66-70 \\
71-75\end{array}$ & $\begin{array}{l}51(19.5 \%) \\
21(18.1 \%) \\
\}_{4}(17.4 \%)\end{array}$ & $\begin{array}{l}210(80.4 \%) \\
95(81.9 \%) \\
\gamma_{19(82.6 \%)}\end{array}$ & $\begin{array}{l}261(65.3 \%) \\
116(29 \%) \\
14(3.5 \%) \\
6(1.5 \%) \\
3(0.75 \%)\end{array}$ & $\begin{array}{l}x^{2}-.149 \\
\text { df }-2 \\
p-.928\end{array}$ \\
\hline 2.Religion & $\begin{array}{l}\text { Hindu } \\
\text { Christian } \\
\text { Muslim }\end{array}$ & $\begin{array}{l}48(21.52 \%) \\
13(20.63 \%) \\
15(13.15 \%)\end{array}$ & $\begin{array}{l}175(78.47 \%) \\
50(79.36 \%) \\
99(86.84 \%)\end{array}$ & $\begin{array}{l}223(55.75 \%) \\
63(15.75 \%) \\
114(28.5 \%)\end{array}$ & $\begin{array}{l}x^{2}-3.287 \\
d f-2 \\
p-.193\end{array}$ \\
\hline $\begin{array}{l}\text { 3.Socieconomic } \\
\text { status }\end{array}$ & $\begin{array}{l}\text { Lower } \\
\text { Upper lower } \\
\text { Low middle } \\
\text { Upper middle } \\
\text { Upper class }\end{array}$ & $\begin{array}{l}0(0) \\
27(25.2 \%) \\
26(16.8 \%) \\
18(20 \%) \\
5(29.4 \%)\end{array}$ & $\begin{array}{l}0(0 \%) \\
80(74.8 \%) \\
129(83.2 \%) \\
72(80 \%) \\
12(70.6 \%)\end{array}$ & $\begin{array}{l}31(7.8 \%) \\
107(26.8 \%) \\
155(38.8 \%) \\
90(22.5 \%) \\
17(4.3 \%)\end{array}$ & $\begin{array}{l}x^{2}-11.728 \\
d f-4 \\
p=0.019\end{array}$ \\
\hline 4.Education & $\begin{array}{l}\text { Illiterate } \\
\text { Primary } \\
\text { Middle school } \\
\text { High school } \\
\text { Intermediate } \\
\text { Graduate }\end{array}$ & $\begin{array}{l}1(6.6 \%) \\
9(16.0 \%) \\
3(7.8 \%) \\
30(26.3 \%) \\
30(22.0 \%) \\
3(27.3 \%)\end{array}$ & $\begin{array}{l}14(93.3 \%) \\
47(83.9 \%) \\
35(92.1 \%) \\
84(73.7 \%) \\
136(81.9 \%) \\
8(72.7 \%)\end{array}$ & $\begin{array}{l}15(3.8 \%) \\
56(14.0 \%) \\
38(9.5 \%) \\
114(28.5 \%) \\
166(41.5 \%) \\
11(2.8 \%)\end{array}$ & $\begin{array}{l}x^{2}-9.869 \\
d f-5 \\
p=.079\end{array}$ \\
\hline $\begin{array}{l}\text { 5.Age of menarche } \\
\text { in years }\end{array}$ & $\begin{array}{l}<12 \\
12 \\
13 \\
14 \text { or more }\end{array}$ & $\begin{array}{l}0 \\
22(27.5 \%) \\
36(15.8 \%) \\
18(4.2 \%)\end{array}$ & $\begin{array}{l}0 \\
57(72.3 \%) \\
158(81.4 \%) \\
109(85.8 \%)\end{array}$ & $\begin{array}{l}0 \\
79(19.6 \%) \\
194(48.5 \%) \\
127(31.8 \%)\end{array}$ & $\begin{array}{l}x^{2}-5.996 \\
d f-2 \\
p=.051\end{array}$ \\
\hline 6.Age of marriage & $\begin{array}{l}<20 \\
20-24 \\
25-29 \\
30 \text { and above }\end{array}$ & $\begin{array}{l}11(24.4 \%) \\
42(18.3 \%) \\
20(18.0 \%) \\
3(21.4 \%)\end{array}$ & $\begin{array}{l}14(74.6 \%) \\
188(81.7 \%) \\
91(82.0 \%) \\
11(78.6 \%)\end{array}$ & $\begin{array}{l}45(11.3 \%) \\
230(57.5 \%) \\
111(27.8 \%) \\
14(3.5 \%)\end{array}$ & $\begin{array}{l}x^{2}-1.072 \\
\text { df }-3 \\
p=.784\end{array}$ \\
\hline 7.Parity & $\begin{array}{l}2 \text { or less } \\
3 \\
4\end{array}$ & $\begin{array}{l}45(21.2 \%) \\
29(16.8 \%) \\
2(13.3 \%)\end{array}$ & $\begin{array}{l}167(78.8 \%) \\
144(83.2 \%) \\
13(86.7 \%)\end{array}$ & $\begin{array}{l}212(53 \%) \\
173(43.3 \%) \\
15(3.8 \%)\end{array}$ & $\begin{array}{l}x^{2}-1.558 \\
d f-2 \\
p=.459\end{array}$ \\
\hline 8.Mode of delivery & $\begin{array}{l}\text { Vaginal } \\
\text { abdominal }\end{array}$ & $\begin{array}{l}57(18.4 \%) \\
19(21.1 \%)\end{array}$ & $\begin{array}{l}253(81.6 \%) \\
71(78.9 \%)\end{array}$ & $\begin{array}{l}310(77.5 \%) \\
90(22.5 \%)\end{array}$ & $\begin{array}{l}x^{2}-.336 \\
\mathrm{df}-1 \\
\mathrm{p}=.562\end{array}$ \\
\hline $\begin{array}{l}\text { 9.Age at last child } \\
\text { birth }\end{array}$ & $\begin{array}{l}<30 \\
30-32 \\
33-35 \\
>35\end{array}$ & $\begin{array}{l}11(19.6 \%) \\
38(17.4 \%) \\
23(20.9 \%) \\
4(25 \%)\end{array}$ & $\begin{array}{l}45(80.4 \%) \\
180(82.6 \%) \\
87(79.1 \%) \\
12(75 \%)\end{array}$ & $\begin{array}{l}56(14 \%) \\
218(55 \%) \\
110(28 \%) \\
16(4 \%)\end{array}$ & $\begin{array}{l}x^{2}-.998 \\
\mathrm{df}-3 \\
\mathrm{p}-.802\end{array}$ \\
\hline $\begin{array}{ll}10 . \text { Age } & \text { of } \\
\text { menopause } & \end{array}$ & $\begin{array}{ll}\text { Less } & \text { than } \\
50 y r s & \\
\text { More } & \text { than } \\
50 y r s & \end{array}$ & $\begin{array}{l}73(19.8 \%) \\
3(9.1 \%)\end{array}$ & $\begin{array}{l}294(80.2 \%) \\
30(90.9 \%)\end{array}$ & $\begin{array}{l}367(91.75 \%) \\
33(8.3 \%)\end{array}$ & $\begin{array}{l}x^{2}-2.295 \\
d f-1 \\
p=.130\end{array}$ \\
\hline
\end{tabular}

Prevalence of gynecological morbidity was virtually same in the two age interval groups (51$55 \& 56-60$ ) which comes to more than $90 \%$ of total women in the study. Compared to Hindus and Christians, prevalence of symptoms was lower among Muslims but the difference was not statistically significant. It was noted that morbidity decreases as one moves from upper lower $(25.2 \%)$ to the middle class $(21.8 \%)$. The observed difference was statistically significant with a $\mathrm{p}$ value of 0.019 (table 2.3). Age of menarche had association with the prevalence of gynecological symptoms in our study with a higher prevalence in the 12 year group $(27.8 \%)$ than in the other age groups ( $\mathrm{p}$ value-0.051).(table 2.5). However no significant association with age of menopause was found. The prevalence of gynecological symptoms was found to decrease as age at marriage increases but the observed difference was not statistically significant. The 
prevalence was slightly more among women who underwent cesarean delivery $(21.1 \%)$ than the normal delivery group $(18.4 \%)$ however the observed difference was not statistically significant.(table 2.8). No significant association was noted with education or parity

Health seeking behavior. It was noteworthy that $39.5 \%$ had not sought relief for their symptoms. The reasons reported were mainly - time constraints (43\%) and shyness (27\%), mildness of symptoms and the thought that symptoms did not need treatment. (Table 3 )

Table 3: Health seeking behavior and reasons

\begin{tabular}{|l|l|}
\hline Heath seeking behavior & $\begin{array}{l}\text { Reasons for not seeking health } \\
\text { care }\end{array}$ \\
\hline Women who had symptoms & Time constraints $-13(43 \%)$ \\
$-76(100 \%)$ & Shyness \\
Women who sought health & Mildness of symptoms $-4(13 \%)$ \\
care- 46(60.5\%) & Thought not relevant - 5(17\%) \\
Women who did not seek & \\
care- 30(39.5\%) & \\
\hline
\end{tabular}

PAP smear examination: Pap smear examination showed Atrophic smear 30.8\%, squamous cells $21.8 \%$, Inflammatory smear $29.8 \%$, NILM $17.8 \%$.

\section{Discussion}

All 400 participants who consented for the interview underwent gynecological examination resulting in a $100 \%$ coverage . This may be due to the proximity of the institution and expectation of good quality service without the minor hassles which they are likely to face in routine outpatient services. In a study conducted in rural women of Pondicherry $15 \%$ of women who participated the interview had refused gynecological examination (4). In the same study (4) the population above $60 \mathrm{yrs}$ was $58 \%$. But in this study $94.2 \%$ was below the age of 60 . May be the nuclear family system prevalent in the urban Trivandrum has contributed to this disparity

Of the study population 55\% were Hindus, $28 \%$ Muslims, $15 \%$ were Christians. This more or less follows the distribution in the state of Kerala as per the 2011 census Compared to Hindus and Christians gynecological morbidity was lower among Muslims in this study but the differences were not statistically significant. In a study in the reproductive age group done in Trivandrum, Hindus were having less gynecological morbidity compared to other religions. The differences in the educational, a economic status and health seeking behavior of the women across the religion also could be the reason. ${ }^{(5)}$. In this study more than $70 \%$ were educated to high school and above. The illiterate was only $3.8 \%$ and this is in agreement with the female literacy rate of $92.07 \%$ as per 2011 census data of Kerala state. Socioeconomic status was assessed using Kuppuswamy scale. $38.9 \%$ of women belonged to lower middle and $28 \%$ belonged to upper lower class. There was significant association of prevalence of gynecological symptoms with lower socioeconomic status which was evident in other studies also $^{(6)}$

Mean age of menarche was 13 years. 22\% had attained menarche at 12years. Prevalence was more in women who attained menarche early, by the age of 12 rather than other age groups and the observed difference was statistically significant ${ }^{(5)}$. Menopause was between $46-50$ years for $88 \%$ of people and the mean age of menopause as calculated from our study was 48.25yrs which agrees to the mean age of 48.26 as reported by

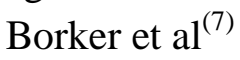

The prevalence of self-reported gynecological symptoms was $19 \%$ in the study population and the gynecological morbidity computed by examination was $23.5 \%$.The prevalence of gynecological morbidity was more when compared to gynecological symptom. This is similar to many studies including that by Susila et al in which at least one gynecological morbidity was $44 . .4 \%$ versus symptom which was $25.9 \% .^{(4,8,9,10)}$ There is wide variation in the prevalence of gynecological morbidities ranging from $43-92 \%$ in various studies ${ }^{(8,9)}$. This may be due to the varying characteristics of population, access to service and difference in the methods of assessing gynecological morbidities. The prevalence in our study was low compared to the 
previous studies ${ }^{(8,9)}$ Probably because it was in an urban population with easy access to health care facilities and the high education status of the participants.

Regarding the pattern of morbidity $9.3 \%$ of women had complaints of excessive discharge per vagina, the majority being white curdy discharge. This was $4.0 \%$ in urban women ${ }^{(11)}$ and $3.3 \%$ in the rural population (4). Symptoms related to urinary tract comprised of $12.3 \%$ in this study which was less than that reported in a rural population $^{(4)}$.

The prevalence of self-reported symptoms of pelvic organ prolapse was $3.5 \%$ and the morbidity detected by examination was $4.75 \%$ in this study. The commonest pelvic organ prolapse detected was cystorectocoele. Symptoms reported by Susila et al was $7.9 \%$ and the morbidity was as high as $18.8 \%$. The grand multipara $(\geq 5$ deliveries) in that study was $47.5 \%$ whereas it was $0 \%$ in this study and para 4 was only $3.8 \%$. Even though certain obstetric factors like parity, mode of delivery, and age at marriage were recognized risk factors for the widely prevalent gynecological diseases like genital prolapse and urinary incontinence $^{(12)}$ this study did not find such significant association because the entire patterns of gynecological morbidities in women were considered together rather than the individual factors.

Bleeding per vagina though minimal was complained by $0.8 \%$ and were taken up for evaluation of postmenopausal bleeding as per the hospital protocol. None of the cervical smear showed suspicious or atypical cells. The majority of smears were atrophic $(30.7 \%)$ or inflammatory $(29.7 \%)$ in nature.

Lower abdominal pain was reported by $2.5 \%$. Sexual problems mainly dyspareunia and vaginal dryness reported was less $(3.3 \%)$ when compared to other studies. Diseases of the vulva, vagina constituted the majority (13.8\%) of which senile /atrophic vaginitis was the leading cause. The picture was similar in other studies and the reported proportion was $15 \%$. $^{(4)}$
Even though the study population had easy access to health facility, nearly $40 \%$ had not sought service from health professional. The reasons reported were time constraints, shyness, and mildness of symptoms. $43 \%$ thought that treatment was not needed. This shows that there was a gap in awareness regarding their symptoms.

\section{Conclusion}

This study had a prevalence of reproductive morbidity of about $23.5 \%$, which is quite low in comparison to other studies across the country.

However it has proved that more than one in five women suffer from this. Despite the proximity of several health institutions around $40 \%$ of the women in this study did not seek health care. If this is the situation in one of the most literate state in India and that too in an urban setting, it means that the reality is far from this. If studies are undertaken in rural and tribal population the incidence is likely to be much higher. It is therefore necessary that women are counseled to seek help early so that diseases can be tackled in the early stage itself to enable them to have a peaceful and fruitful old age

\section{References}

1. World Health Organization. Interpreting reproductive health: ICPD+5 Forum, The Hague, 8-12 February 1999.Geneva: World Health Organization; 1999.

Unpublished

document WHO/CHS/RHR/99.7.

2. Sauvaget C, Ramadas K, Fayette JM, Thomas G, Thara S, Sankaranarayanan R. Socio-economic factors \& longevity in a cohort of Kerala State, India. Indian Journal of Medical Research. 2011 May 1;133(5):479. ( at 40 men \&women live for $35 \& 37$ yrs respectively Longevity

3. Graham WJ. Outcomes and effectiveness in reproductive health. Social Science \& Medicine. 1998 Dec 31;47(12):1925-36.

4. Susila T ,Roy G Gynecological morbidities in a population of Rural 
Postmenopausal Women in Pondicherry :Uncovering the hidden Base of the iceberg The Journal of Obstetrics and Gynecology of India (Jan .Feb 2014)64(1):53-58

5. Abraham A, Varghese S, Satheesh M, Vijayakumar K, Gopakumar S, Mendez A. Pattern of gynecological morbidity, its factors and Health seeking behavior among reproductive age group women in a rural community of Thiruvananthapuram district, South Kerala. Indian Journal of Community Health. 2014 Sep 20;26(3):230-7.

6. Ravindra, T K S. Women's Health in a Rural Poor Population in Tamil Nadu.in Women's Health Situation in a Rural Population Edited by T. K. Sundari Ravindra, p.175-211.

7. Borker SA, Venugopalan PP, Bhat SN. Study of menopausal symptoms, and perceptions about menopause among women at a rural community in Kerala. Journal of mid-life health. $2013 \mathrm{Jul}$ 1;4(3):182.

8. Bang RA, Baitule M, Sarmukaddam S, Bang AT, Choudhary Y, Tale O. High prevalence of gynaecological diseases in rural Indian women. The Lancet. 1989 Jan 14;333(8629):85-8.

9. Latha K, Kanani SJ, Maitra N, Bhatt RV, Senapati SK. Prevalence of clinically detectable gynaecological morbidity in India: results of four community based studies. Journal of familywelfare. 1997 Dec 1;43(4):8-16.

10. Sehgal A, Singh A, Kumar R, Gupta I. An epidemiological study of Gynaecological morbidity in rural community of Haryana India. The female client and the health care provider. 1995:129-37.
11. Ankita Goyal, Neha Mishra, Shraddha Dwiedi A Comparative study of morbidity pattern among rural and urban postmenopausal women of Allahabad, Uttarpradesh ,India, Int. J. Res Med Sci. 2017 Feb ;5(2)670-677

12. .MacLennan AH, Taylor AW, Wilson DH, Wilson D. The prevalence of pelvic floor disorders and their relationship to gender, age, parity and mode of delivery. BJOG: An International Journal of Obstetrics \& Gynaecology. 2000 Dec 1;107(12):146070. 